\title{
Rationale for stereotactic body radiation therapy in treating patients with oligometastatic hormone-naïve prostate
}

\section{cancer}

\section{Onita Bhattasali ${ }^{1}$, Leonard N. Chen ${ }^{1}$, Michael Tong ${ }^{1}$, Siyuan Lei ${ }^{1}$, Brian T. Collins ${ }^{1}$, Pranay Krishnan ${ }^{2}$, Christopher Kalhorn ${ }^{3}$, John H. Lynch ${ }^{4}$, Simeng Suy ${ }^{1}$, Anatoly Dritschilo ${ }^{1}$, Nancy A. Dawson ${ }^{5}$ and Sean P. Collins ${ }^{1 *}$}

1 Department of Radiation Medicine, Georgetown University Hospital, Washington, DC, USA

2 Department of Radiology, Georgetown University Hospital, Washington, DC, USA

${ }^{3}$ Department of Neurosurgery, Georgetown University Medical Center, Washington, DC, USA

${ }^{4}$ Department of Urology, Georgetown University Hospital, Washington, DC, USA

${ }^{5}$ Department of Oncology, Lombardi Comprehensive Cancer Center, Georgetown University Medical Center, Washington, DC, USA

\section{Edited by:}

Nam Phong Nguyen, International

Geriatric Radiotherapy Group, USA

Reviewed by:

Jaroslaw T. Hepel, Brown University, USA

Johnny Kao, Good Samaritan Hospital

Medical Center, USA

${ }^{*}$ Correspondence:

Sean P. Collins, Department of

Radiation Medicine, Georgetown

University Medical Center, 3800

Reservoir Road, NW, Washington, DC

20007, USA

e-mail: spc9@georgetown.edu
Despite advances in treatment for metastatic prostate cancer, patients eventually progress to castrate-resistant disease and ultimately succumb to their cancer. Androgen deprivation therapy (ADT) is the standard treatment for metastatic prostate cancer and has been shown to improve median time to progression and median survival time. Research suggests that castrate-resistant clones may be present early in the disease process prior to the initiation of ADT. These clones are not susceptible to ADT and may even flourish when androgen-responsive clones are depleted. Stereotactic body radiation therapy (SBRT) is a safe and efficacious method of treating clinically localized prostate cancer and metastases. In patients with a limited number of metastatic sites, SBRT may have a role in eliminating castrate-resistant clones and possibly delaying progression to castrate-resistant disease.

Keywords: prostate cancer, SBRT, IGRT, cyberknife, oligometastases, hormone-naïve

\section{STEREOTACTIC BODY RADIATION THERAPY}

Radiation oncologists strive to maximize tumor control while minimizing normal tissue toxicity. Over the past several years, advances in image-guided radiation treatment (IGRT) have allowed the treatment of tumors with increased efficacy and reduced toxicity (1-4). For example, stereotactic body radiation therapy (SBRT) may improve tumor control and reduce treatment-related toxicity through improved targeting and management of tumor motion (5). Accurate tumor targeting means that radiation may be delivered with relatively narrow margins to account for uncertainty in target position. This allows for high-dose, extremely hypofractionated treatment courses (1-5 fractions) that may be more radiobiologically effective and are certainly more convenient for patients $(6,7)$. For example, the CyberKnife Radiosurgical System (Accuray) is capable of localizing the prostate and adjusting the radiation beam accordingly in real time throughout a treatment fraction (8). This feature allows for a reduction in the planning target volume (PTV) and therefore better limits the dose to adjacent rectum and bladder (Figure 1). Multi-institutional experience demonstrates that this technology

Abbreviations: ADT, androgen deprivation therapy; CRPC, castrate-resistant prostate cancer; DVH, dose-volume histogram; GTV, gross target volume; IGRT, image-guided radiation treatment; LHRH, luteinizing hormone-releasing hormone; PAP, prostatic acid phosphatase; PSA. prostate-specific antigen; PTV, planning target volume; SBRT, stereotactic body radiation therapy; TURP, transurethral resection of the prostate. allows investigators to administer higher doses to the prostate with biochemical disease-free survival and toxicity rates similar to conventional treatments (9-14). It is hoped that SBRT will also positively impact patient outcomes in patients with limited metastatic disease.

\section{OLIGOMETASTASES}

Patients with controlled primaries and "oligometastatic" disease may experience long-term stability in the number of metastatic sites (15). Oligometastatic prostate cancer has been defined as five or fewer sites due to the more favorable outcomes seen in these patients (Figure 2) (16). Hellman and Weichselbaum first proposed the existence of oligometastatic disease as a clinically significant state separate from polymetastatic disease and suggested a more causal relationship between the size or grade of a tumor and its propensity for metastatic spread (17). Corbin et al. expanded on this concept suggesting the development of a specific oligometastatic phenotype over the natural course of a cancer's evolution that is less aggressive than other metastatic phenotypes (18). This theory has been corroborated by microRNA analysis of clinically limited metastatic disease that accurately characterizes which patients will remain oligometastatic and which patients will proceed to polymetastatic disease (19). For patients with limited metastatic sites, SBRT to the oligometastases may offer long-term disease control and impact survival (20). Data are emerging that patients with limited asymptomatic metastases may experience improved diseasefree survival and quality of life after SBRT (21). We hypothesize 


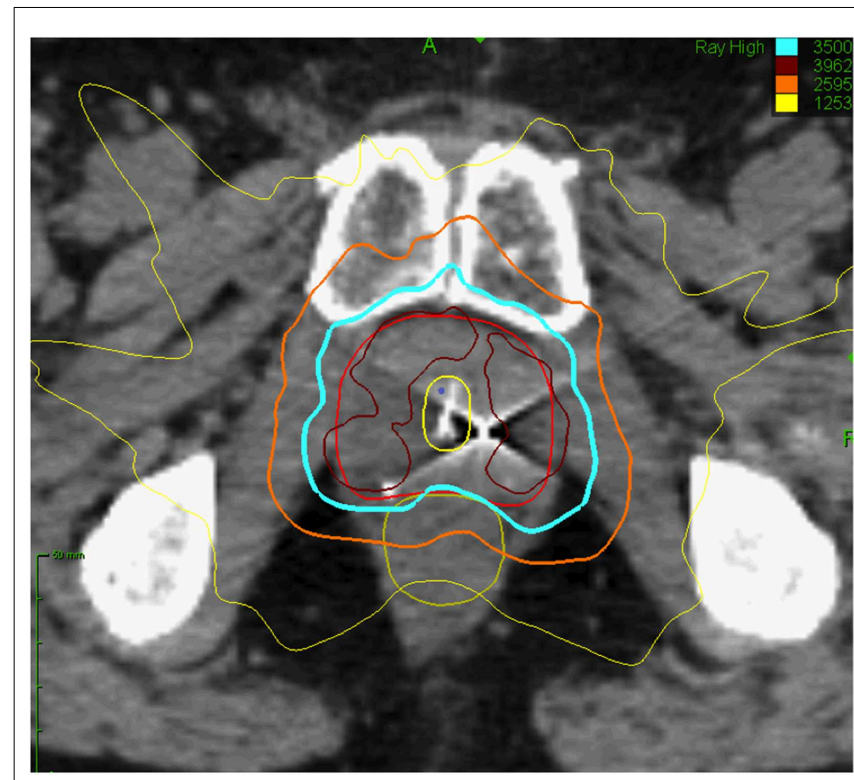

FIGURE 1 | Prostate SBRT: treatment planning axial computed tomography images demonstrating the prostate (red line), prostatic urethra (yellow), and rectum (green line). Isodose lines shown as follows: $115 \%$ of the prescription dose, maroon line; $100 \%$ of the prescription dose, light blue line: $75 \%$ of the prescription dose, orange line; and $35 \%$ of the prescription dose, green line. that in oligometastatic prostate cancer patients, androgen deprivation therapy (ADT) would eliminate micrometastatic disease while SBRT would eradicate large tumor deposits that may be more likely to develop castrate-resistant clones.

\section{ANDROGEN DEPRIVATION THERAPY FOR METASTATIC PROSTATE CANCER}

The current treatment for newly diagnosed metastatic prostate cancer is hormone ablation via luteinizing hormone-releasing hormone (LHRH) analog until disease progression (22). The response rate for primary hormonal therapy for men with metastatic prostate cancer exceeds $80 \%$ and the median duration of response is approximately $18-24$ months (22). Patients with high volume metastatic disease have a poorer prognosis with a median time to prostate-specific antigen (PSA) progression of about only 10 months and median time to clinical progression (e.g., worsening bone metastases) of about 14 months (23). In contrast, patients with low volume metastatic disease have a 22 -month median time to PSA progression with androgen ablation alone and median time to clinical progression of more than 3 years (23). The median overall survival for men commencing androgen ablation with clinically evident metastatic disease is about 30 months (22). Survival varies depending on the extent of disease and location of the bone metastases (16, 23-27). All patients will ultimately progress despite the initial success of this approach. Castrate-resistant prostate cancer (CRPC) remains an incurable disease resulting in considerable morbidity. Alternative hormonal agents or chemotherapy may
A

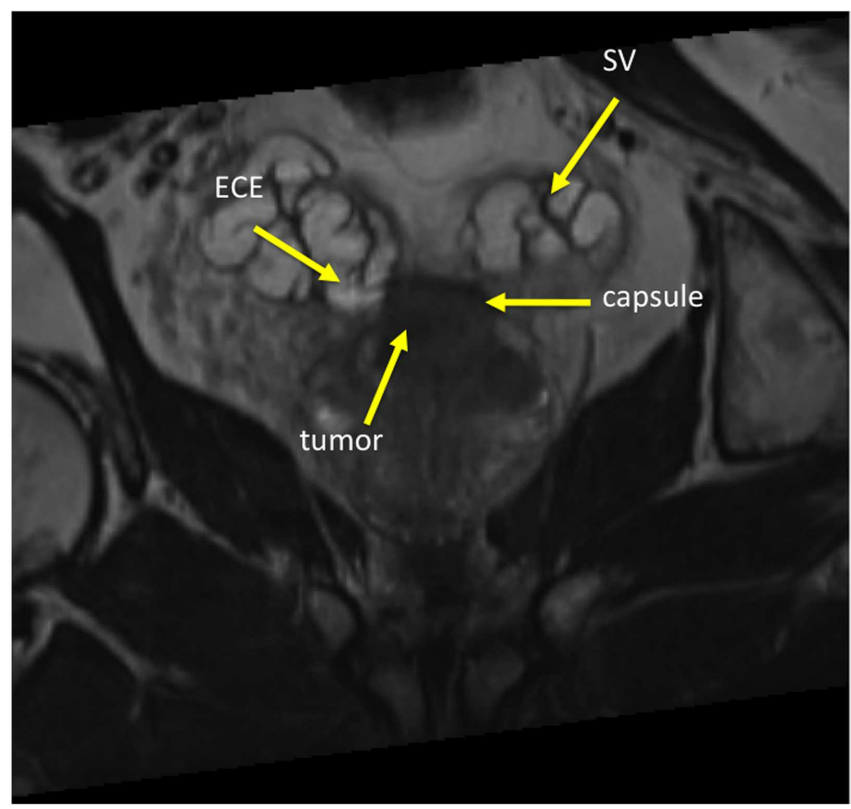

B

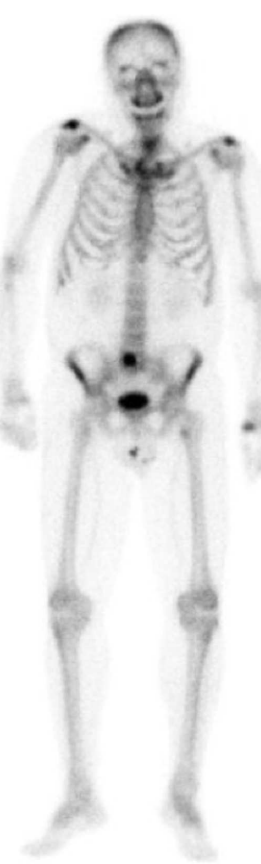

RT Anterior LT
FIGURE 2 | Sixty-year-old gentleman with oligometastatic prostate cancer. He presented with back pain and his PSA was $35 \mathrm{ng} / \mathrm{ml}$. DRE was abnormal and imaging revealed: (A) Coronal T2-weighted multiplanar reconstruction $\mathrm{MRI}$ image demonstrating extracapsular extension into the seminal vesicles. (B) Bone scan demonstrating a solitary L 5 vertebral body metastasis. 
be employed at the time of castrate resistance and provide small overall survival benefits (28).

\section{CHEMOTHERAPEUTIC AGENTS FOR CASTRATE-RESISTANT PROSTATE CANCER}

Early investigation of chemotherapeutic agents for metastatic CRPC showed that mitoxantrone combined with prednisone improved pain and quality of life when compared to prednisone alone $(29,30)$. Unfortunately, mitoxantrone did not prolong survival in randomized trials $(31,32)$. Docetaxel was the first chemotherapeutic agent able to demonstrate increased survival in metastatic CRPC in addition to decreased pain and improved quality of life (33). Median survival increased by 2.9 months in the cohort who received docetaxel compared to mitoxantrone.

The breakthrough with docetaxel has led to subsequent advances in systemic therapy for metastatic prostate cancer. Multiple hormonal and non-hormonal agents have emerged in recent phase III clinical trials that demonstrate increased overall survival time (outlined in Tables 1 and 2) (34-39). Hormonal agents target adrenal testosterone production that is shielded from conventional ADT. Abiraterone inhibits androgen production by blocking enzymes crucial to testosterone synthesis (34). Enzalutamide does not lower intratumoral testosterone but is a potent androgen receptor antagonist that acts by blocking androgen activity within cancer cells (36). Novel non-hormonal agents have also been efficacious in the setting of CRPC. Sipuleucel-T is a therapeutic cancer vaccine that acts as an immunostimulant specifically targeting the prostatic acid phosphatase (PAP) antigen found on prostate cancer cells (37). Radium-223 is a radiopharmaceutical agent that targets bony tissue and destroys metastatic prostate cancer cells through alpha particle emission (38). Additional phase III trials with newer agents are underway. To date, no single agent has demonstrated a PSA response rate greater than $54 \%$ or an overall survival benefit greater than 5 months, and further innovation through new agents or combination regimens is necessary to optimize survival.

\section{RATIONALE FOR TREATMENT OF THE PROSTATE IN THE PRESENCE OF OLIGOMETASTATIC DISEASE}

We believe an effective radiotherapeutic approach in the prostate may improve long-term outcomes with limited toxicity in patients with oligometastatic disease. The addition of prostate radiotherapy to ADT has been shown to significantly improve progressionfree survival and overall survival with acceptable morbidity in patients with locally advanced prostate cancer $(40,41)$. While a slight increase in overall bother from urinary and bowel symptoms may occur from combined therapy, the difference is minimal and does not meet the threshold for clinical significance (42). The SPCG-7/SFUO-3 trial for patients with locally advanced prostate cancer achieved a $12 \%$ reduction in 10 -year prostate cancer specific mortality when radiotherapy was combined with endocrine treatment (41). The trial observed a 10 -year overall survival benefit of $8.9 \%$ consistent with a 7 -year overall survival benefit of $8 \%$ with the addition of radiation therapy in the NCIC CTG PR.3/MRC UK PR07 trial (40, 41).

The mechanism of such benefit is currently unclear. Castrateresistant clones may be present in the prostate prior to the initiation of $\mathrm{ADT}$ and they could be enriched through clonal selection after testosterone decline (Figure 3) (43). Animal models support the use of early local treatment to eliminate androgenindependent clones $(44,45)$. Radiotherapy, which eradicates androgen-sensitive and androgen insensitive clones with similar efficacy, may be effective at eradicating androgen-independent clones. This has the potential to delay the time to castrate resistance and hence prolong disease control.

Studies in which routine post-radiotherapy prostate biopsies have been performed following primary ADT reveal a high rate of persistence of local disease (46). In the SPCG-7 trial, the postradiation therapy biopsy positivity rate was an unacceptable $66 \%$ (46). Local control is important in this malignancy, as problems resulting from uncontrolled local disease are significant including urinary obstruction (47). Palliative transurethral resection of the prostate (TURP) and/or radiation therapy may be less effective than primary treatment when the disease burden is lower $(48,49)$.

Table 1 | Prostate-specific antigen response rate of new chemotherapeutic agents for metastatic CRPC.

\begin{tabular}{|c|c|c|c|c|c|c|c|}
\hline Trial & $\begin{array}{l}\text { Treatment } \\
\text { group }\end{array}$ & Drug class & Mechanism of action & Control group & $\begin{array}{l}\text { Treatment } \\
\text { group response } \\
\text { rate }(\%)\end{array}$ & $\begin{array}{l}\text { Control } \\
\text { group response } \\
\text { rate }(\%)\end{array}$ & $P$-value \\
\hline TAX 327 & $\begin{array}{l}\text { Docetaxel + } \\
\text { prednisone }\end{array}$ & Taxoid & $\begin{array}{l}\text { Microtubule disassembly } \\
\text { inhibitor }\end{array}$ & $\begin{array}{l}\text { Mitoxantrone }+ \\
\text { prednisone }\end{array}$ & 45 & 32 & $<0.001$ \\
\hline TROPIC & $\begin{array}{l}\text { Cabazitaxel + } \\
\text { prednisone }\end{array}$ & Taxoid & $\begin{array}{l}\text { Microtubule disassembly } \\
\text { inhibitor }\end{array}$ & $\begin{array}{l}\text { Mitoxantrone }+ \\
\text { prednisone }\end{array}$ & 39.2 & 17.8 & $=0.0002$ \\
\hline COU-AA301 & $\begin{array}{l}\text { Abiraterone + } \\
\text { prednisone }\end{array}$ & Hormonal agent & $\begin{array}{l}\text { Cytochrome P4S0 17A1 } \\
\text { inhibitor }\end{array}$ & $\begin{array}{l}\text { Placebo }+ \\
\text { prednisone }\end{array}$ & 29 & 6 & $<0.001$ \\
\hline AFFIRM & En2alutamide & Hormonal agent & Androgen receptor antagonist & Placebo & 54 & 2 & $<0.001$ \\
\hline IMPACT & Sipuleucel-T & Cancer vaccine & $\begin{array}{l}\text { PA2024 activated peripheral- } \\
\text { blood mononuclear cells }\end{array}$ & Placebo & 2.6 & 1.3 & $\begin{array}{l}\text { Not } \\
\text { significant }\end{array}$ \\
\hline ALSYMPCA & Radium-223 & Radio pharmaceutical & Bone-targeted alpha radiation & Placebo & 16 & 6 & $<0.001$ \\
\hline
\end{tabular}


Table 2 | Overall survival benefit of new chemotherapeutic agents for metastatic CRPC.

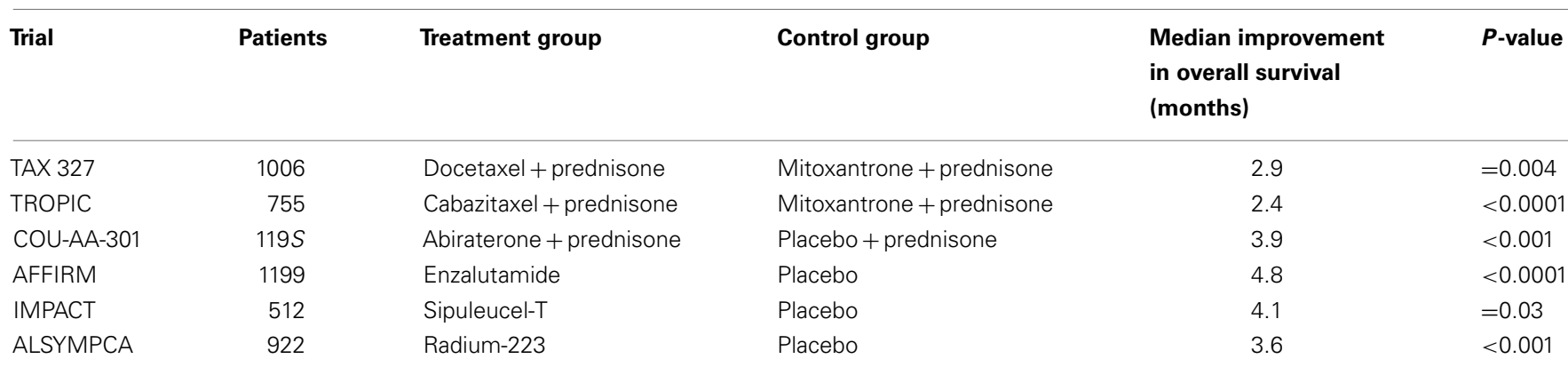

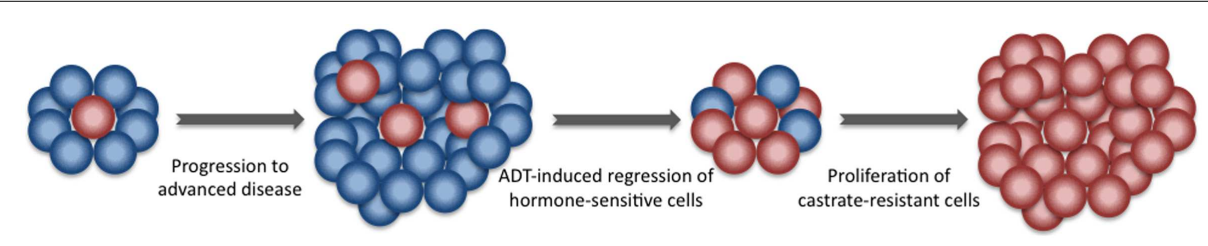

FIGURE 3 | Development of castrate-resistant prostate cancer. Newly diagnosed prostate cancer is composed of a group of heterogeneous cells. The majority is hormone-sensitive. A minority are castration-resistant.
Following the initiation of ADT, castration-resistant cells have a survival advantage and give rise to a more aggressive castration-resistant prostate cancer.
It is also evident that local failures can lead to a second wave of distant metastases (50). Achieving improved local control within the prostate therefore carries promise of reducing the sequelae attributable to uncontrolled local disease as well as the prevention of new metastases.

Prostate cancer growth is dependent on androgen activation of androgen receptors. ADT decreases testicular androgens. Although testes are the major source of testosterone in normal men, the intratumoral synthesis of testosterone from weak adrenal androgens appears to be a substantial source of intraprostatic androgen following ADT (51). Intraprostatic androgen synthesis may protect primary prostate cancer cells from ADT and provide a sanctuary for prostate cancer cells to progress to castrate resistance. We propose that SBRT may eliminate this sanctuary delaying the emergence of castrate resistance.

\section{RATIONALE FOR TREATMENT OF BONE OLIGOMETASTASES}

Prostate cancer has a tropism for bone, making it the most common, and frequently the only, site of metastatic disease (52-54). Greater than $80 \%$ of men with metastatic prostate cancer have radiographic evidence of bone involvement. Skeletal complications are a major cause of morbidity in men with prostate cancer. Early in the natural history of the disease, bone metastases are generally asymptomatic, but ultimately at least $40 \%$ of patients will be affected by bone pain, $20 \%$ will experience a pathologic fracture, and 5\% will develop a spinal cord compression. Collectively, skeletal metastases can lead to decreased performance status and devastating neurologic injury. Bone-targeted therapy, such as zoledronic acid and denosumab, decrease but do not eliminate the morbidity associated with bone lesions (55-57). Radiation therapy is typically reserved for symptomatic disease, when the burden of disease is greater and morbidity such as fracture may not be avoidable. Delaying radiation therapy to this point might limit its efficacy in reducing bone morbidity.

Recent reports have suggested that SBRT is safe and effective in treating bone lesions involving long bones and the spinal column $(58,59)$. Earlier studies administered hypofractionated regimens more similar to conventional radiotherapy delivery with doses of $50 \mathrm{~Gy}$ in 10 fractions (21). Several questions remain given the lack of long-term data compared to more conventional radiation therapy. No optimal SBRT regimen has been established due to the variation in target volume and proximity to normal structures (60). However, SBRT has been administered up to $48 \mathrm{~Gy}$ in 3 fractions to multiple metastatic sites simultaneously, and results have shown promising long-term disease control with minimal grade $3+$ toxicity (61). The potential benefits of combining radiation with systemic agents has also been demonstrated $(62,63)$.

Patients treated with SBRT at oligometastatic sites have demonstrated excellent outcomes. Among a cohort of patients with oligometastatic disease and detectable PSA, 100\% achieved local control with SBRT to the metastatic lesions, and over half the patients achieved an undetectable or declining PSA by a median follow up of 4.8 months (64). In another study of men with oligometastases following prostate treatment, salvage SBRT deferred initiation of ADT with a 2-year local control rate of $100 \%$ and a clinical progression-free survival of $42 \%$ (65). Neither study observed grade $3+$ toxicity. Larger studies with more homogeneous patient populations are required to define the potential benefits of SBRT in the setting of prostate cancer. In addition, further research is needed to determine the potential impact of SBRT on systemic disease when combined with immunostimulating agents such as sipuleucel-T (66).

Limited data exist on how radiation dose and fractionation affect the risk of fracture following radiation therapy. Pathologic 


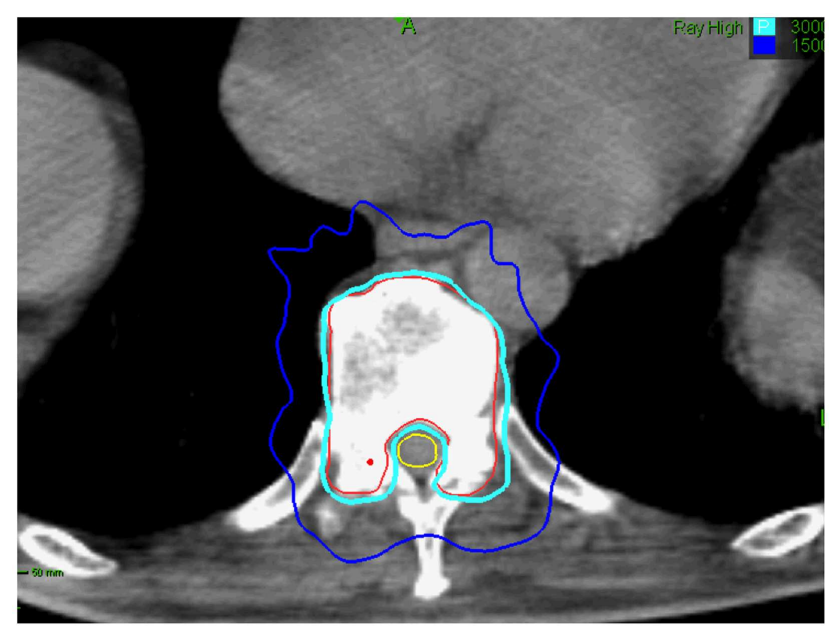

FIGURE 4 | Seventy-five-year-old gentleman with oligometastatic prostate cancer and a T11 vertebral body metastasis. The decision was to proceed with ADT and SBRT. ADT was initiated. The vertebral body was treated with $30 \mathrm{~Gy}$ in 5 fractions. Treatment planning axial computed tomography images demonstrating the GTV (red) and spinal cord (yellow). Isodose lines shown as follows: $100 \%$ of the prescription dose (light blue line) and $50 \%$ of the prescription dose (dark blue line). The maximum point to the spinal cord and esophagus were 30 and $35 \mathrm{~Gy}$, respectively (69).

vertebral body fractures have been described in patients treated with SBRT. They are more common when the lesion is lytic and $\geq 20 \%$ of the vertebral body is involved (67). Vertebral body fracture progression may occur in $40 \%$ of vertebrae treated with single-dose SBRT (67). Treating patients early in the disease course to decrease the extent of bone/vertebral body involvement at the time of SBRT treatment and fractionation may reduce the likelihood of normal bone injury (Figure 4) (68).

\section{TREATMENT TOXICITY AND QUALITY OF LIFE}

We hypothesize that SBRT will decrease tumor burden in the prostate and bone and hence improve long-term well-being. However, if SBRT to the prostate and oligometastases caused a significant rate of high-grade late toxicity and/or adversely affected patients' long-term quality of life this approach would not be worth pursuing further. Prostate SBRT may cause urinary and rectal injury while bone SBRT may promote fractures. The severity and duration of these toxicities varies among patients and has never been prospectively assessed in this patient population. Patients receiving primary ADT have a quality of life that is indistinguishable from a matched normal male population and a quality of life significantly better than that of men with castrateresistant disease (70). Our experience suggests that prostate SBRT will not adversely affect this (71).

\section{CONCLUSION}

Castrate-resistant prostate cancer remains a complex and incurable disease. ADT is successful in delaying the progression to castrate-resistant disease and improving overall survival. Unfortunately, castrate-resistant clones may be present early in the disease process even prior to initiation of ADT, creating the need for alternative treatments. Several chemotherapeutic agents have been developed to treat metastatic prostate cancer, but the benefits of these drugs have been small to date. Radiation therapy is effective for treating bone metastases but is typically reserved for late-stage, symptomatic disease. SBRT has been demonstrated as a safe and efficacious modality for bone lesions. Implementation of SBRT early in the disease process may decrease the morbidity associated with bone lesions and reduce overall tumor burden, in turn delaying progression of disease and improving both the quality and length of life.

\section{AUTHOR CONTRIBUTIONS}

Onita Bhattasali and Leonard N. Chen are lead authors who participated in manuscript drafting, table/figure creation, and manuscript revision. Michael Tong aided in table/figure creation. Siyuan Lei is the dosimetrist who contributed dosimetric data and figures. Pranay Krishnan aided in figure creation. Anatoly Dritschilo, Christopher Kalhorn, Simeng Suy, Brian T. Collins, John H. Lynch, and Nancy A. Dawson are senior authors who aided in drafting the manuscript and manuscript revision. Sean P. Collins is the corresponding author who initially developed the concept, and drafted and revised the manuscript. All authors read and approved the final manuscript.

\section{ACKNOWLEDGMENTS}

This work was supported by NIH Grant P30CA051008.

\section{REFERENCES}

1. Crook JM, Raymond Y, Salhani D, Yang H, Esche B. Prostate motion during standard radiotherapy as assessed by fiducial markers. Radiother Oncol (1995) 37(1):35-42. doi:10.1016/0167-8140(95)01613-L

2. Dawson LA, Mah K, Franssen E, Morton G. Target position variability throughout prostate radiotherapy. Int J Radiat Oncol Biol Phys (1998) 42(5):1155-61. doi:10.1016/S0360-3016(98)00265-X

3. Litzenberg DW, Balter JM, Hadley SW, Sandler HM, Willoughby TR, Kupelian $\mathrm{PA}$, et al. Influence of intrafraction motion on margins for prostate radiotherapy. Int J Radiat Oncol Biol Phys (2006) 65(2):548-53. doi:10.1016/j.ijrobp.2005. 12.033

4. Kupelian PA, Langen KM, Willoughby TR, Zeidan OA, Meeks SL. Image-guided radiotherapy for localized prostate cancer: treating a moving target. Semin Radiat Oncol (2008) 18(1):58-66. doi:10.1016/j.semradonc.2007.09.008

5. Timmerman RD, Kavanagh BD, Cho LC, Papiez L, Xing L. Stereotactic body radiation therapy in multiple organ sites. J Clin Oncol (2007) 25(8):947-52. doi:10.1200/JCO.2006.09.7469

6. Miles EF, Robert Lee W. Hypofractionation for prostate cancer: a critical review. Semin Radiat Oncol (2008) 18(1):41-47. doi:10.1016/j.semradonc.2007.09.006

7. Fowler JF. The radiobiology of prostate cancer including new aspects of fractionated radiotherapy. Acta Oncol (2005) 44(3):265-76. doi:10.1080/ 02841860410002824

8. Xie Y, Djajaputra D, King CR, Hossain S, Ma L, Xing L. Intrafractional motion of the prostate during hypofractionated radiotherapy. Int J Radiat Oncol Biol Phys (2008) 72(1):236-46. doi:10.1016/j.ijrobp.2008.04.051

9. King CR, Brooks JD, Gill H, Presti JC Jr. Long-term outcomes from a prospective trial of stereotactic body radiotherapy for low-risk prostate cancer. Int J Radiat Oncol Biol Phys (2012) 82(2):877-82. doi:10.1016/j.ijrobp.2010.11.054

10. King CR, Collins SP, Fuller D, Wang PC, Kupelian PA, Steinberg M, et al. Health related quality of life after stereotactic body radiotherapy for localized prostate cancer: results from a multi-institutional consortium of prospective trials. Int J Radiat Oncol Biol Phys (2013) 87(5):939-45. doi:10.1016/j.ijrobp.2013.08.019

11. King CR, Freeman DE, Kaplan ID, Fuller D, Bolzicco G, Collins SP, et al. Stereotactic body radiotherapy for localized prostate cancer: pooled analysis from a multi-institutional consortium of prospective phase II trials. Radiother Oncol (2013). doi:10.1016/j.radonc.2013.08.030 
12. Freeman DE, Friedland J, Masterson-McGary M, Spellberg D. Stereotactic body radiotherapy: an emerging treatment approach for localized prostate cancer. Int J Radiat Oncol Biol Phys (2009) 75(3):S307-8. doi:10.1016/j.ijrobp.2009.07.706

13. McBride SM, Wong DS, Dombrowski JJ, Harkins B, Tapella P, Hanscom HN, et al. Hypofractionated stereotactic body radiotherapy in low risk prostate adenocarcinoma. Cancer (2012) 118(15):3681-90. doi:10.1002/cncr.26699

14. Katz AJ, Santoro M, Diblasio F, Ashley R. Stereotactic body radiotherapy for localized prostate cancer: disease control and quality of life at 6 years. Radiat Oncol (2013) 8(1):118. doi:10.1186/1748-717X-8-118

15. Weichselbaum RR, Hellman S. Oligometastases revisited. Nat Rev Clin Oncol (2011) 8(6):378-82. doi:10.1038/nrclinonc.2011.44

16. Singh D, Yi WS, Brasacchio RA, Muhs AG, Smudzin T, Williams JP, et al. Is there a favorable subset of patients with prostate cancer who develop oligometastases? Int J Radiat Oncol Biol Phys (2004) 58(1):3-10. doi:10.1016/S0360-3016(03) 01442-1

17. Hellman S, Weichselbaum RR. Oligometastases. J Clin Oncol (1995) 13(1):8-10.

18. Corbin KS, Hellman S, Weichselbaum RR. Extracranial oligometastases: a subset of metastases curable with stereotactic radiotherapy. J Clin Oncol (2013) 31(11):1384-90. doi:10.1200/JCO.2012.45.9651

19. Lussier YA, Xing HR, Salama JK, Khodarev NN, Huang Y, Zhang Q, et al. MicroRNA expression characterizes oligometastasis(es). PLoS One (2011) 6(12):e28650. doi:10.1371/journal.pone.0028650

20. Alongi F, Arcangeli S, Filippi AR, Ricardi U, Scorsetti M. Review and uses of stereotactic body radiation therapy for oligometastases. Oncologist (2012) 17(8):1100-7. doi:10.1634/theoncologist.2012-0092

21. Milano MT, Katz AW, Zhang H, Okunieff P. Oligometastases treated with stereotactic body radiotherapy: long-term follow-up of prospective study. Int J Radiat Oncol Biol Phys (2012) 83(3):878-86. doi:10.1016/j.ijrobp.2011.08.036

22. Prostate Cancer Trialists' Collaborative G. Maximum androgen blockade in advanced prostate cancer: an overview of the randomised trials. Lancet (2000) 355(9214):1491-8. doi:10.1016/S0140-6736(00)02163-2

23. Eisenberger MA, Blumenstein BA, Crawford ED, Miller G, McLeod DG, Loehrer PJ, et al. Bilateral orchiectomy with or without flutamide for metastatic prostate cancer. N Engl J Med (1998) 339(15):1036-42. doi:10.1056/ NEJM199810083391504

24. Glass TR, Tangen CM, Crawford ED, Thompson I. Metastatic carcinoma of the prostate: identifying prognostic groups using recursive partitioning. J Urol (2003) 169(1):164-9. doi:10.1016/S0022-5347(05)64059-1

25. Rana A, Chisholm GD, Khan M, Sekharjit SS, Merrick MV, Elton RA. Patterns of bone metastasis and their prognostic significance in patients with carcinoma of the prostate. Br J Urol (1993) 72(6):933-6. doi:10.1111/j.1464-410X.1993. tb16301.x

26. Soloway MS, Hardeman SW, Hickey D, Todd B, Soloway S, Raymond J, et al. Stratification of patients with metastatic prostate cancer based on extent of disease on initial bone scan. Cancer (1988) 61(1):195-202. doi:10.1002/10970142(19880101)61:1<195::AID-CNCR2820610133>3.0.CO;2-Y

27. Yamashita K, Denno K, Ueda T, Komatsubara Y, Kotake T, Usami M, et al. Prognostic significance of bone metastases in patients with metastatic prostate cancer. Cancer (1993) 71(4):1297-302. doi:10.1002/1097-0142(19930215)71:4<1297: :AID-CNCR2820710421>3.0.CO;2-S

28. Higano CS, Crawford ED. New and emerging agents for the treatment of castration-resistant prostate cancer. Urol Oncol (2011) 29(Suppl 6):1-8. doi: 10.1016/j.urolonc.2011.08.013

29. Tannock IF, Osoba D, Stockler MR, Ernst DS, Neville AJ, Moore MJ, et al. Chemotherapy with mitoxantrone plus prednisone or prednisone alone for symptomatic hormone-resistant prostate cancer: a Canadian randomized trial with palliative end points. J Clin Oncol (1996) 14(6):1756-64.

30. Osoba D, Tannock IF, Ernst DS, Neville AJ. Health-related quality of life in men with metastatic prostate cancer treated with prednisone alone or mitoxantrone and prednisone. J Clin Oncol (1999) 17(6):1654.

31. Kantoff PW, Halabi S, Conaway M, Picus J, Kirshner J, Hars V, et al. Hydrocortisone with or without mitoxantrone in men with hormone-refractory prostate cancer: results of the cancer and leukemia group B 9182 study. J Clin Oncol (1999) 17(8):2506.

32. Berry W, Dakhil S, Modiano M, Gregurich M, Asmar L. Phase III study of mitoxantrone plus low dose prednisone versus low dose prednisone alone in patients with asymptomatic hormone refractory prostate cancer. J Urol (2002) 168(6):2439-43. doi:10.1016/S0022-5347(05)64163-8
33. Berthold DR, Pond GR, Soban F, de Wit R, Eisenberger M, Tannock IF. Docetaxel plus prednisone or mitoxantrone plus prednisone for advanced prostate cancer: updated survival in the TAX 327 study. J Clin Oncol (2008) 26(2):242-5. doi:10.1200/JCO.2007.12.4008

34. De Bono JS, Logothetis CJ, Molina A, Fizazi K, North S, Chu L, et al. Abiraterone and increased survival in metastatic prostate cancer. $N$ Engl J Med (2011) 364(21):1995-2005. doi:10.1056/NEJMoa1014618

35. de Bono JS, Oudard S, Ozguroglu M, Hansen S, Machiels J-P, Kocak I, et al. Prednisone plus cabazitaxel or mitoxantrone for metastatic castrationresistant prostate cancer progressing after docetaxel treatment: a randomised open-label trial. Lancet (2010) 376(9747):1147-54. doi:10.1016/S01406736(10)61389-X

36. Scher HI, Fizazi K, Saad F, Taplin M-E, Sternberg CN, Miller K, et al. Increased survival with enzalutamide in prostate cancer after chemotherapy. $N$ Engl J Med (2012) 367(13):1187-97. doi:10.1056/NEJMoa1207506

37. Kantoff PW, Higano CS, Shore ND, Berger ER, Small EJ, Penson DF, et al. Sipuleucel-T immunotherapy for castration-resistant prostate cancer. $N$ Engl J Med (2010) 363(5):411-22. doi:10.1056/NEJMoa1001294

38. Parker C, Nilsson S, Heinrich D, Helle SI, O’Sullivan JM, Fosså SD, et al. Alpha emitter radium-223 and survival in metastatic prostate cancer. $N$ Engl J Med (2013) 369(3):213-23. doi:10.1056/NEJMoa1213755

39. Tannock IF, de Wit R, Berry WR, Horti J, Pluzanska A, Chi KN, et al. Docetaxel plus prednisone or mitoxantrone plus prednisone for advanced prostate cancer. N Engl J Med (2004) 351(15):1502-12. doi:10.1056/NEJMoa040720

40. Warde P, Mason M, Ding K, Kirkbride P, Brundage M, Cowan R, et al. Combined androgen deprivation therapy and radiation therapy for locally advanced prostate cancer: a randomised, phase 3 trial. Lancet (2012) 378(9809):2104-11. doi:10.1016/S0140-6736(11)61095-7

41. Widmark A, Klepp O, Solberg A, Damber J-E, Angelsen A, Fransson P, et al. Endocrine treatment, with or without radiotherapy, in locally advanced prostate cancer (SPCG-7/SFUO-3): an open randomised phase III trial. Lancet (2009) 373(9660):301-8. doi:10.1016/S0140-6736(08)61815-2

42. Fransson P, Lund J-A, Damber J-E, Klepp O, Wiklund F, Fosså S, et al. Quality of life in patients with locally advanced prostate cancer given endocrine treatment with or without radiotherapy: 4-year follow-up of SPCG-7/SFUO-3, an open-label, randomised, phase III trial. Lancet Oncol (2009) 10(4):370-80. doi:10.1016/S1470-2045(09)70027-0

43. Ahmed M, Li LC. Adaptation and clonal selection models of castrationresistant prostate cancer: current perspective. Int J Urol (2012) 20(4):362-71. doi:10.1111/iju.12005

44. Craft N, Chhor C, Tran C, Belldegrun A, DeKernion J, Witte ON, et al. Evidence for clonal outgrowth of androgen-independent prostate cancer cells from androgen-dependent tumors through a two-step process. Cancer Res (1999) 59(19):5030-6.

45. Gingrich JR, Barrios RJ, Kattan MW, Nahm HS, Finegold MJ, Greenberg NM. Androgen-independent prostate cancer progression in the TRAMP model. Cancer Res (1997) 57(21):4687-91.

46. Solberg A, Haugen OA, Viset T, Bergh A, Tasdemir I, Ahlgren G, et al. Residual prostate cancer in patients treated with endocrine therapy with or without radical radiotherapy: a side study of the SPCG-7 randomized trial. Int J Radiat Oncol Biol Phys (2011) 80(1):55-61. doi:10.1016/j.ijrobp.2010.01.072

47. Khafagy R, Shackley D, Samuel J, O’Flynn K, Betts C, Clarke N. Complications arising in the final year of life in men dying from advanced prostate cancer. $J$ Palliat Med (2007) 10(3):705-11. doi:10.1089/jpm.2006.0185

48. Crain DS, Amling CL, Kane CJ. Palliative transurethral prostate resection for bladder outlet obstruction in patients with locally advanced prostate cancer. $J$ Urol (2004) 171(2):668-71. doi:10.1097/01.ju.0000104845.24632.92

49. Din OS, Thanvi N, Ferguson CJ, Kirkbride P. Palliative prostate radiotherapy for symptomatic advanced prostate cancer. Radiother Oncol (2009) 93(2):192-6. doi:10.1016/j.radonc.2009.04.017

50. Fuks Z, Leibel SA, Wallner KE, Begg CB, Fair WR, Anderson LL, et al. The effect of local control on metastatic dissemination in carcinoma of the prostate: long-term results in patients treated with 1251 implantation. Int J Radiat Oncol Biol Phys (1991) 21(3):537-47. doi:10.1016/0360-3016(91) 90668-T

51. Cai C, Balk SP. Intratumoral androgen biosynthesis in prostate cancer pathogenesis and response to therapy. Endocr Relat Cancer (2011) 18(5):R175-82. doi:10.1530/ERC-10-0339 
52. Coleman RE. Metastatic bone disease: clinical features, pathophysiology and treatment strategies. Cancer Treat Rev (2001) 27(3):165-76. doi:10.1053/ctrv. 2000.0210

53. Saylor PJ, Lee RJ, Smith MR. Emerging therapies to prevent skeletal morbidity in men with prostate cancer. J Clin Oncol (2011) 29(27):3705-14. doi:10.1200/JCO.2010.34.4994

54. Saad F, Olsson C, Schulman CC. Skeletal morbidity in men with prostate cancer: quality-of-life considerations throughout the continuum of care. Eur Urol (2004) 46(6):731-40. doi:10.1016/j.eururo.2004.08.016

55. Saad F, Gleason DM, Murray R, Tchekmedyian S, Venner P, Lacombe L, et al. A randomized, placebo-controlled trial of zoledronic acid in patients with hormone-refractory metastatic prostate carcinoma. J Natl Cancer Inst (2002) 94(19):1458-68. doi:10.1093/jnci/94.19.1458

56. Fizazi K, Carducci M, Smith M, Damião R, Brown J, Karsh L, et al. Denosumab versus zoledronic acid for treatment of bone metastases in men with castration-resistant prostate cancer: a randomised, double-blind study. Lancet (2011) 377(9768):813-22. doi:10.1016/S0140-6736(10)62344-6

57. Saad F, Gleason DM, Murray R, Tchekmedyian S, Venner P, Lacombe L, et al. Long-term efficacy of zoledronic acid for the prevention of skeletal complications in patients with metastatic hormone-refractory prostate cancer. J Natl Cancer Inst (2004) 96(11):879-82. doi:10.1093/jnci/djh295

58. Jhaveri P, Teh BS, Bloch C, Amato R, Butler EB, Paulino A. Stereotactic body radiotherapy in the management of painful bone metastases. Oncology (2008) 22(7):782.

59. Wang XS, Rhines LD, Shiu AS, Yang JN, Selek U, Gning I, et al. Stereotactic body radiation therapy for management of spinal metastases in patients without spinal cord compression: a phase 1-2 trial. Lancet Oncol (2012) 13(4):395-402. doi:10.1016/S1470-2045(11)70384-9

60. Salama JK, Kirkpatrick JP, Yin F-F. Stereotactic body radiotherapy treatment of extracranial metastases. Nat Rev Clin Oncol (2012) 9:654-65. doi:10.1038/ nrclinonc.2012.166

61. Salama JK, Hasselle MD, Chmura SJ, Malik R, Mehta N, Yenice KM, et al. Stereotactic body radiotherapy for multisite extracranial oligometastases. Cancer (2012) 118(11):2962-70. doi:10.1002/cncr.26611

62. Kao J, Packer S, Vu HL, Schwartz ME, Sung MW, Stock RG, et al. Phase 1 study of concurrent sunitinib and image-guided radiotherapy followed by maintenance sunitinib for patients with oligometastases. Cancer (2009) 115(15):3571-80. doi: $10.1002 / \mathrm{cncr} .24412$

63. Kao J, Chen C-T, Tong CC, Packer SH, Schwartz M, Chen S-H, et al. Concurrent sunitinib and stereotactic body radiotherapy for patients with oligometastases. Target Oncol (2013). doi:10.1007/s11523-013-0280-y

64. Ahmed KA, Barney BM, Davis BJ, Park SS, Kwon ED, Olivier KR. Stereotactic body radiation therapy in the treatment of oligometastatic prostate cancer. Front Oncol (2012) 2:215. doi:10.3389/fonc.2012.00215

65. Berkovic P, De Meerleer G, Delrue L, Lambert B, Fonteyne V, Lumen N, et al. Salvage stereotactic body radiotherapy for patients with limited prostate cancer metastases: deferring androgen deprivation therapy. Clin Genitourin Cancer (2012) 11(1):27-32. doi:10.1016/j.clgc.2012.08.003

66. Gulley JL, Arlen PM, Bastian A, Morin S, Marte J, Beetham P, et al. Combining a recombinant cancer vaccine with standard definitive radiotherapy in patients with localized prostate cancer. Clin Cancer Res (2005) 11(9):3353-62. doi:10.1158/1078-0432.CCR-04-2062

67. Rose PS, Laufer I, Boland PJ, Hanover A, Bilsky MH, Yamada J, et al. Risk of fracture after single fraction image-guided intensity-modulated radiation therapy to spinal metastases. J Clin Oncol (2009) 27(30):5075-9. doi:10.1200/JCO. 2008.19.3508

68. Sahgal A, Atenafu EG, Chao S, Al-Omair A, Boehling N, Balagamwala $\mathrm{EH}$, et al. Vertebral compression fracture after spine stereotactic body radiotherapy: a multi-institutional analysis with a focus on radiation dose and the spinal instability neoplastic score. J Clin Oncol (2013) 31(27):3426-31. doi:10.1200/JCO.2013.50.1411

69. Benedict SH, Yenice KM, Followill D, Galvin JM, Hinson W, Kavanagh B, et al. Stereotactic body radiation therapy: the report of AAPM Task Group 101. Med Phys (2010) 37:4078. doi:10.1118/1.3438081

70. Albertsen PC, Aaronson NK, Muller MJ, Keller SD, Ware JE Jr. Health-related quality of life among patients with metastatic prostate cancer. Urology (1997) 49(2):207-17. doi:10.1016/S0090-4295(96)00485-2

71. Chen LN, Suy S, Uhm S, Oermann EK, Ju AW, Chen V, et al. Stereotactic body radiation therapy (SBRT) for clinically localized prostate cancer: the Georgetown University experience. Radiat Oncol (2013) 8(1):58. doi:10.1186/1748717X-8-58

Conflict of Interest Statement: Sean P. Collins and Brian T. Collins serve as clinical consultants to Accuray Inc. The other authors declare that they have no competing interests.

Received: 07 October 2013; accepted: 18 November 2013; published online: 03 December 2013.

Citation: Bhattasali O, Chen LN, Tong M, Lei S, Collins BT, Krishnan P, Kalhorn C, Lynch JH, Suy S, Dritschilo A, Dawson NA and Collins SP (2013) Rationale for stereotactic body radiation therapy in treating patients with oligometastatic hormone-naïve prostate cancer. Front. Oncol. 3:293. doi: 10.3389/fonc.2013.00293

This article was submitted to Radiation Oncology, a section of the journal Frontiers in Oncology.

Copyright () 2013 Bhattasali, Chen, Tong, Lei, Collins, Krishnan, Kalhorn, Lynch, Suy, Dritschilo, Dawson and Collins. This is an open-access article distributed under the terms of the Creative Commons Attribution License (CC BY). The use, distribution or reproduction in other forums is permitted, provided the original author (s) or licensor are credited and that the original publication in this journal is cited, in accordance with accepted academic practice. No use, distribution or reproduction is permitted which does not comply with these terms. 